\title{
Microplastic abundance and distribution in the open water and sediment of the Ottawa River, Canada, and its tributaries
}

\author{
Jesse C. Vermaire ${ }^{a b}$, Carrington Pomeroy ${ }^{a}$, Sofia M. Herczegh ${ }^{a}$, Owen Haggart ${ }^{a}$, and \\ Meaghan Murphy ${ }^{c}$ \\ ${ }^{a}$ Institute of Environmental Science, Carleton University, 1125 Colonel By Drive, Ottawa, ON K1S 5B6, \\ Canada; ${ }^{b}$ Department of Geography and Environmental Studies, Carleton University, 1125 Colonel By \\ Drive, Ottawa, ON K1S 5B6, Canada; ${ }^{c}$ Ottawa Riverkeeper, 301-1960 Scott Street, Ottawa, ON K1Z 8L8, \\ Canada \\ *iesse.vermaire@carleton.ca
}

\section{OPEN ACCESS}

Citation: Vermaire JC, Pomeroy C, Herczegh SM, Haggart O, and Murphy M. 2017. Microplastic abundance and distribution in the open water and sediment of the Ottawa River, Canada, and its tributaries. FACETS 2: 301-314. doi: | 0.1 | 39/facets-20 | 6-0070

Editor: Daniel E. Schindler

Received: November 28, 2016

Accepted: January 26, 2017

Published: March 21, 2017

Copyright: (C) 2017 Vermaire et al. This work is licensed under a Creative Commons Attribution 4.0 International License (CC BY 4.0), which permits unrestricted use, distribution, and reproduction in any medium, provided the original author(s) and source are credited.

Published by: Canadian Science Publishing

\begin{abstract}
Microplastic pollution is prevalent in the Ottawa River, with all open water samples $(n=62)$ and sediment samples $(n=10)$ containing microplastics. The median microplastic concentration of nearshore $100 \mathrm{~L}$ water samples was 0.1 fragments per $\mathrm{L}$ (ranged between 0.05 and 0.24 fragments per $\mathrm{L}$ ). The larger volume Manta trawls samples taken in the middle of the Ottawa River had an overall mean concentration of plastics of 1.35 fragments per $\mathrm{m}^{3}$. Plastic concentrations were significantly higher downstream of the wastewater treatment plant $\left(1.99\right.$ fragments per $\left.\mathrm{m}^{3}\right)$ compared with upstream of the effluent output $\left(0.71\right.$ fragments per $\left.\mathrm{m}^{3}\right)$, suggesting that the effluent plume is a pathway for plastic pollution to the Ottawa River. The mean concentration of microplastic fragments recovered in the sediment samples was 0.22 fragments per g dry weight. The abundance of microplastics in the sediment was not significantly related to the mean particle size or the organic content of the sediment. The most common form of plastic particles found was microfibers. These made up between $70 \%$ and $100 \%$ of all plastic particles observed, although plastic microbeads and secondary plastic fragments were also recovered.
\end{abstract}

Key words: microplastics, Ottawa River, plastic pollution, Anthropocene, environmental change, sewage effluent

\section{Introduction}

Plastics are ubiquitous in today's society, and plastic pollution is one of the defining legacies of humans on the earth. In fact, over the last half century, plastic pollution has been synonymous with human society to the point that it has recently been proposed as a defining feature of the Anthropocene, a newly proposed geological epoch in which humans are a dominant force affecting the earth system (Waters et al. 2016).

In 2015, global plastic production was estimated at 322 million metric tons (Plastics-the Facts 2016), and the vast majority of plastic products are inexpensive and intended to be disposable. This has resulted in massive quantities of plastics being produced and thus disposed of on an annual basis. Plastic polymers do not biodegrade at timescales relevant for human society (i.e., multiple centuries to millennia or longer), but are broken down by UV radiation and mechanical forces into 
smaller and smaller strands of polymers (Barnes et al. 2009). This breakdown, but lack of biological degradation, results in a buildup of small plastic fragments, which has been most extensively studied in marine environments (Cole et al. 2011). These small plastic particles can have negative impacts on aquatic ecosystems including concentrating other contaminants in the system (Gregory 1996; Rios et al. 2007) and being ingested by animals, including apex predators, reducing their fitness and increasing mortality (Provencher et al. 2015; Sigler 2014; Lönnstedt and Eklöv 2016; Holland et al. 2016).

In aquatic pollution studies, plastic fragments are divided into two main groups based on size: microplastics ( $\leq 5 \mathrm{~mm}$ ) and macroplastics ( $>5 \mathrm{~mm}$; Masura et al. 2015). Microplastics found in natural systems can come from a variety of sources. Primary microplastics are manufactured by industry; for example, microbeads in cosmetics, toothpaste, and face wash, or microfibers from synthetic clothing and rope (Thompson et al. 2009). Secondary microplastics are the result of the breakdown of larger plastic fragments by erosion, solar radiation, water currents, and freezing and thawing (Barnes et al. 2009).

Microplastic pollution in marine environments is well established (Cole et al. 2011). It is only recently, however, that the presence of microplastics in freshwater systems has been reported (Eriksen et al. 2013; Castañeda et al. 2014; Baldwin et al. 2016), and there is still a limited understanding of where microplastics are occurring in freshwater systems and the controls on their abundance and distribution (Wagner et al. 2014; Anderson et al. 2016). In Canada, few studies have examined plastic pollution of freshwater outside of the Great Lakes/St. Lawrence system, and there is a lack of knowledge of the presence and concentration of plastics in Canadian freshwater systems (Anderson et al. 2016). The goals of this study were threefold. First we quantified the abundance of microplastics in the open water of the Ottawa River and its larger tributaries within the boundaries of the National Capital Region (including the cities of Ottawa, Ontario, and Gatineau, Quebec) to establish microplastic concentrations for this system. We then investigated microplastic pollution upstream and downstream of the city of Ottawa effluent plume in the Ottawa River to test if this effluent plume is a source of microplastics to the Ottawa River. Finally, we quantified the abundance of microplastics in river sediment samples along a depositional gradient to test if microplastic concentrations in the sediments were related to the depositional environment of the river.

\section{Study region}

The Ottawa River is a recently designated Canadian Heritage River and holds substantial cultural, ecological, and economic importance to Canada. The river flows for approximately $1271 \mathrm{~km}$, west from northern Quebec into Lake Temiskaming, and then southeast along the border of Ontario and Quebec before emptying into Lake of Two Mountains and the St. Lawrence River in southeastern Quebec. The catchment area of the Ottawa River is $146300 \mathrm{~km}^{2}$, larger than the size of England, and encompasses large areas of wetlands, boreal forest, and temperate forest in its southern reaches. Sampling took place in Canada's National Capital Region, which includes the Canadian capital city of Ottawa as well as the neighboring city of Gatineau (Quebec) and smaller towns and rural communities with an approximate population of 1.23 million people.

\section{Methods}

\section{Field sampling}

To quantify the abundance of microplastics, surface water samples were collected in the summer of 2016 from sampling sites chosen to give a good representation of the Ottawa River watershed within the National Capital Region, both below and above the city of Ottawa's wastewater treatment plant. 
These sites included locations along the Ottawa River, Rideau River, Rideau Canal and Brewery Creek, and effluent ponds at the city of Ottawa wastewater treatment plant. Water sampling for plastics was performed using two methods: (1) a nearshore bottle sampling method that filtered $100 \mathrm{~L}$ by hand, making it highly portable; and (2) a Manta trawl method that sampled a greater volume of water $(\sim 100000 \mathrm{~L})$ and was ideal for comparisons with other microplastic research in large lake and marine environments, but challenging to deploy in a variety of shallower sites. The bottle sampling method was performed nearshore in flowing water at a depth of $0.5 \mathrm{~m}$ below the water's surface. At each bottle sampling site, $4 \mathrm{~L}$ plastic jugs were used to filter $100 \mathrm{~L}$ of water through $100 \mu \mathrm{m}$ nylon mesh. This was repeated three times at each location. Before use in the field, each filter was examined under a stereomicroscope to ensure that there was no microplastic contamination on the filter and then placed into a sterile Whirl-Pak bag until use. In the field, the filters were carefully removed from the Whirl-Pak bag and placed on the end of a metal cylinder and secured at the base by a hose clamp before water filtration. After each $100 \mathrm{~L}$ sample of water was filtered, the filters were carefully removed from the metal cylinder and placed directly back into a Whirl-Pak bag and sealed. Samples were kept refrigerated at $4{ }^{\circ} \mathrm{C}$ until processed in the laboratory.

Three $100 \mathrm{~L}$ effluent samples were also collected from the city of Ottawa wastewater treatment plant for microplastic analysis. Effluent samples were obtained from the final holding tank at the wastewater treatment plant before the effluent is released into the river. Effluent samples were collected from approximately $15 \mathrm{~cm}$ below the surface using an ISCO peristaltic pump and filtered using a $100 \mu \mathrm{m}$ nylon mesh similar to the bottle sampling method used in the river water sampling.

To sample a larger volume of water specifically upstream and downstream of the effluent plume from the city of Ottawa's wastewater treatment plant, Manta trawls, using a $100 \mu \mathrm{m}$ mesh size, were taken from a boat above and below the Ottawa wastewater treatment effluent plume. The Manta net was deployed three times both above and below the effluent plume off the stern of the boat at surface depth for 20 min time intervals. To estimate the volume of water entering the Manta net, the flow of water entering the net was measured in meters per second using a Global Water flow meter. The total volume of water sampled by the Manta net varied between 84 and $181 \mathrm{~m}^{3}$ (mean $=128 \mathrm{~m}^{3}$, standard deviation $=37 \mathrm{~m}^{3}$ ) and was estimated based on the size of the Manta net opening ( area $=0.116 \mathrm{~m}^{2}$ ), the average flow rate of the sampling interval, and the duration of the sampling interval. Following each Manta trawl, the material retained in the Manta net was washed through a clean $30 \mu \mathrm{m}$ nylon mesh filter that was then sealed in a Whirl-Pak bag and kept refrigerated until processing. Between each sample, the Manta net was backwashed with river water, and the sock at the end of the Manta net was washed with deionized water in an effort to limit crosscontamination between sampling locations.

To quantify microplastic concentrations in the sediment along a depositional gradient, 10 sediment samples were collected in the fall of 2015 near Petrie Island in the Ottawa River using an Ekman bottom grab sampler with a sample volume of $3.5 \mathrm{~L}$. The sampling site was selected because of its location downstream of the city of Ottawa's wastewater treatment plant and because there is a large depositional gradient from sandy bottom sediment to fine silts and clays to test if plastic concentrations varied with depositional environment. Between each sample, the Ekman sampler was rinsed with river water and the river sediment was placed in sealed plastic bags and refrigerated until processing in the laboratory.

\section{Laboratory and statistical analyses}

In the laboratory, each surface water sample and effluent sample was washed from the mesh filter into a beaker using distilled water and underwent a wet hydrogen peroxide $\left(\mathrm{H}_{2} \mathrm{O}_{2}\right)$ oxidation using a $30 \% \mathrm{H}_{2} \mathrm{O}_{2}$ solution heated to $80{ }^{\circ} \mathrm{C}$ for $7 \mathrm{~h}$ to remove organic material from the sample. 
Following the wet oxidation, the resulting sample was filtered a second time through a clean $100 \mu \mathrm{m}$ filter. The content in the filter was then backwashed with distilled water into a Petri dish and examined under a Leica stereomicroscope at $40 \times$ magnification for microplastics. The microplastics observed were enumerated, and larger fragments were isolated from the sample with forceps for permanent storage. It should be noted that this filtering and visual inspection methodology does not take into account microplastic particles less than $100 \mu \mathrm{m}$ that would pass through the filter and would have been difficult to reliably identify under a stereomicroscope at $40 \times$ magnification.

In addition to freshwater and effluent samples collected in the field, samples of tap water taken from Carleton University were processed in the same manner as the river water samples to serve as control samples for possible contamination with microplastics in the laboratory or during processing. For these control samples, $100 \mathrm{~L}$ of tap water were filtered through the same apparatus using the same $4 \mathrm{~L} \mathrm{Nalgene} \mathrm{plastic} \mathrm{bottles} \mathrm{as} \mathrm{the} \mathrm{river} \mathrm{water} \mathrm{samples.} \mathrm{These} \mathrm{control} \mathrm{samples} \mathrm{then} \mathrm{underwent} \mathrm{wet}$ $\mathrm{H}_{2} \mathrm{O}_{2}$ oxidation at the same time and location as the field samples using the same equipment. The control samples were then inspected under the stereomicroscope and any microplastic particles observed were counted.

The sediment samples required greater processing than the surface water samples to isolate microplastics because the sediment samples contained much more material retained by the initial sieving. Sediment sample preparation for the isolation of microplastics followed Masura et al. (2015) but omitted the first density separation. A $400 \mathrm{~g}$ sample of wet sediment was dried in an oven at $100{ }^{\circ} \mathrm{C}$ for $24 \mathrm{~h}$ to calculate the dry mass of the sediment. The dried sediment sample was then dispersed using a $5 \%$ sodium hexametaphosphate solution and mixed with a magnetic stir bar for $1 \mathrm{~h}$. The dispersed sample was then passed through a $0.3 \mathrm{~mm}$ sieve and washed clean. The material retained in the $0.3 \mathrm{~mm}$ sieve was transferred to a beaker and underwent wet $\mathrm{H}_{2} \mathrm{O}_{2}$ oxidation using $300 \mathrm{~mL}$ of $30 \% \mathrm{H}_{2} \mathrm{O}_{2}$ to remove organic material. The sample material was then sieved through a $100 \mu \mathrm{m}$ sieve and washed, and the material remaining in the sieve was then transferred to a $500 \mathrm{~mL}$ beaker. The sample material then underwent a density separation using a sodium chloride $(\mathrm{NaCl})$ solution of $6 \mathrm{~g}$ of salt per $20 \mathrm{~mL}$ of sample solution to separate plastic material from the denser sediment (Masura et al. 2015). The salt solution and material were then transferred to a separation funnel and allowed to settle for $30 \mathrm{~min}$. The sediment that settled at the bottom of the separation funnel was then removed, examined for microplastics under a stereomicroscope, and discarded. The solution that remained in the separation funnel was then passed through a $100 \mu \mathrm{m}$ sieve, thoroughly washed with deionized water to remove all salt, and then backwashed into a Petri dish and examined for microplastics under a Leica stereomicroscope at $40 \times$ magnification. Observed microplastic particles were counted, and larger fragments were removed from the Petri dish with forceps and permanently stored.

The organic content and grain size of the sediment were calculated to characterize the depositional environment of the sample site. To determine the organic content of the sediment, a loss-on-ignition analysis was performed using standard methodology (Heiri et al. 2001). Dry sediment (1 cc) was heated in a muffle furnace to $550^{\circ} \mathrm{C}$ for $4 \mathrm{~h}$, and the organic content of the sediment was estimated based on the weight loss of the sediment. The mean particle size of the sediment sample was determined using a Coulter laser diffraction analysis conducted on prepared sediment. For particle size analysis, $1 \mathrm{cc}$ of sediment underwent wet $\mathrm{H}_{2} \mathrm{O}_{2}$ oxidation at $80^{\circ} \mathrm{C}$ for $7 \mathrm{~h}$ to remove organic matter. Following oxidation, a 5\% sodium hexametaphosphate solution was added to the sample as a dispersant for $24 \mathrm{~h}$ before the sample underwent particle size analysis. The arithmetic mean particle size of the sample was calculated using GRADISTAT version 8 (Blott and Pye 2001).

For the Manta net sample, to test if microplastic concentrations were greater downstream from the city of Ottawa effluent plume, a two-sided $t$ test was carried out comparing samples above and below 
the effluent plume. For the sediment samples, to test if the depositional environment of the system is correlated to microplastic abundance, a nonparametric Spearman's rank correlation test was performed to compare the abundance of microplastics (number of pieces of microplastic per $\mathrm{kg}$ of dry sediment) to the organic matter content and mean particle size of the sediment sample. All statistical analyses and graphing were carried out in $\mathrm{R}$ version 3.3.1 (R Development Core Team 2016), and the map was produced using ARCMap version 10.4.1 by Esri.

\section{Results}

Microplastics were found in every single surface water sample collected from the Ottawa River and its tributaries $(n=62)$. With the bottle sampling method, plastic concentrations ranged from a low of 0.05 plastic fragments per $\mathrm{L}$ at the confluence of the Madawaska River into the Ottawa River to a high of 0.24 fragments per L in the Rideau River (site a in Fig. 1). The greatest median concentration of plastics was observed in water samples from the Rideau Canal ( 0.19 fragments per $\mathrm{L}$ ), followed closely by samples collected at Petrie Island in the Ottawa River ( 0.18 fragments per $\mathrm{L}$ ), which is downstream from where the Ottawa wastewater treatment plant releases effluent into the Ottawa River (site $h$ in Fig. 1). The overall median plastic concentration observed for surface water samples using the $100 \mathrm{~L}$ filtering technique was 0.1 fragments per L. Interestingly, samples collected directly from the effluent tank using a pump had some of the lowest plastic concentrations observed in all of our samples (median $=0.07, n=3$ ), suggesting that at the time, plastic concentrations were low at our sampling depth.

Using the bottle sampling method, not only were plastic fragments detected in all of our surface water samples, but they were also detected in approximately $80 \%$ of our tap water samples (9 out of 11 samples). Although the median concentration of plastics in the tap water samples ( 0.02 fragments per $\mathrm{L}$ ) is an order of magnitude lower than the median plastic concentration of the field samples ( 0.1 fragments per $\mathrm{L}$ ) and there was significantly more plastic in the field samples compared with the tap water controls based on a Kruskal-Wallis test $(p<0.001)$, these results highlight the potential for the contamination of microplastic samples and the need for laboratory controls to assess the level of contamination.

The vast majority of plastic fragments recovered were microfibers (Fig. 2). Using the bottle sampling method, $>95 \%$ of plastic fragments recovered were microfibers with the remainder of the sample consisting of microbeads and unidentified plastic fragments. The Manta net sampling was also dominated by plastic microfibers (mean $73 \%$ of plastic particles), but there was a greater proportion of microbeads (mean $7 \%$ of plastic particles) and other plastic fragments (mean 20\% of plastic fragments).

The Manta trawl samples allowed for a much larger volume of water to be filtered than the bottle sampling method, giving a better approximation of plastic concentrations in the open water environment but at a reduced spatial coverage because it requires that the site is accessible by boat. Each $20 \mathrm{~min}$ Manta trawl filtered between approximately 84000 and $180000 \mathrm{~L}$ of water depending on the velocity of the river's flow and the speed of the boat. Based on the Manta trawls, plastic concentrations in the Ottawa River below the effluent output $\left(1.99\right.$ fragments per $\left.\mathrm{m}^{3}\right)$ were 2.8 times greater than plastic concentrations above the effluent output $\left(0.71\right.$ fragments per $\left.\mathrm{m}^{3}\right)$ and statistically significant based on a two-sided $t$ test $(t=-4.97, \mathrm{df}=3.99, p=0.008)$. Based on the Manta trawl sampling, the overall mean concentration of plastics in the open water of the Ottawa River was 1.35 fragments per $\mathrm{m}^{3}$ (Fig. 3). Estimates of plastic concentrations based on the Manta trawl are systematically lower than those estimates based on the bottle sampling method, which may reflect differences in sampling location (e.g., middle of river vs. edge of river) or in sampling methodology (small vs. large volume samples). 


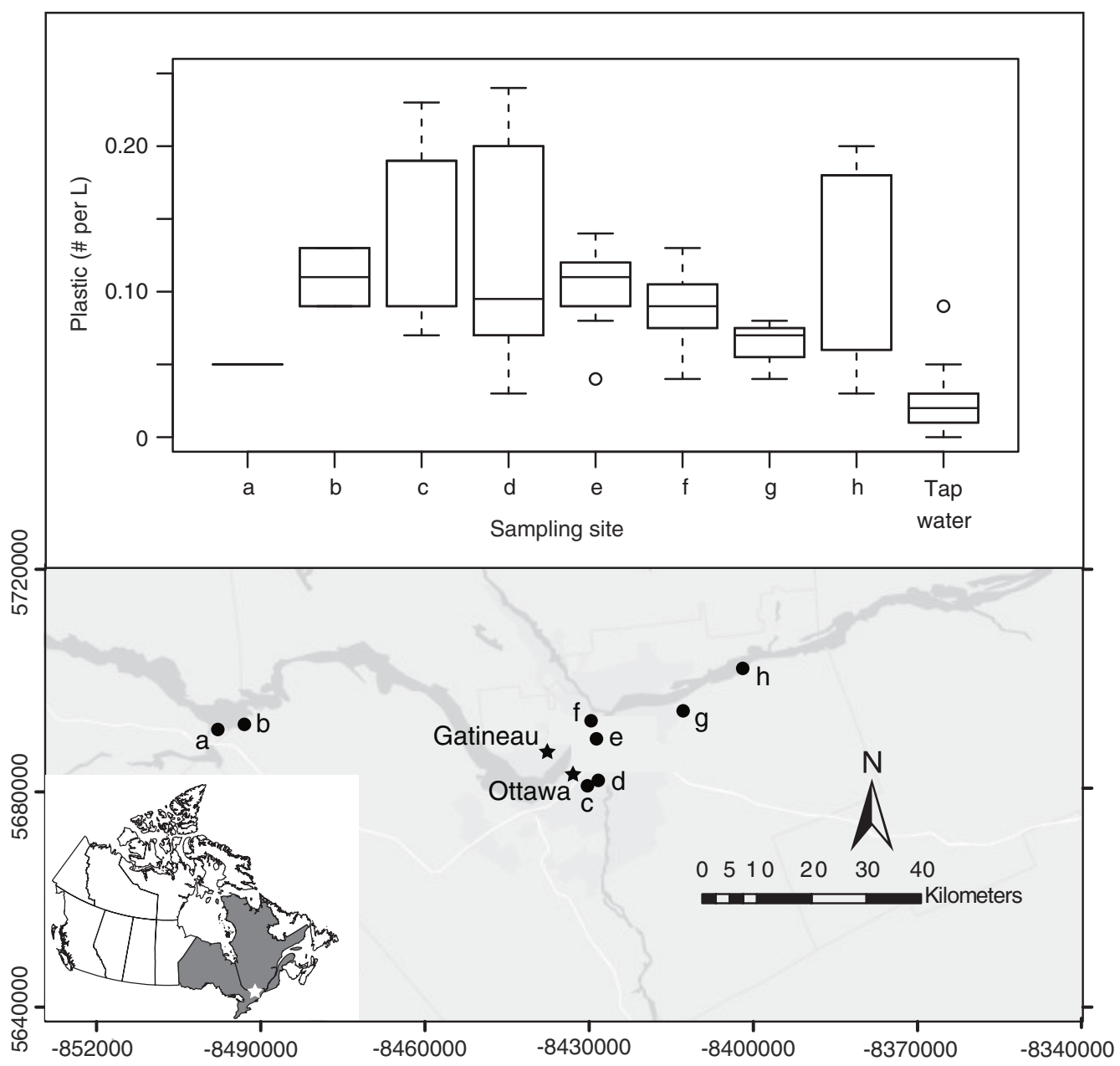

Fig. 1. Boxplot showing plastic concentrations and map showing sampling locations for the $100 \mathrm{~L}$ bottle sampling method in the (a) Madawaska River, (b) Mississippi River, (c) Rideau Canal, (d) Rideau River, (e) Ottawa River upstream of wastewater treatment plant, (f) Brewery Creek, (g) wastewater treatment plant, and (h) Ottawa River at Petrie Island downstream of wastewater treatment plant. Map attributions: Esri, HERE, DeLorme, MapmyIndia, ( O OpenStreetMap contributors, and the GIS user community.

Microplastics were recovered from every sediment sampling location (Fig. 4). Similar to the open water samples, the microplastics observed in the sediment samples were dominated by microfibers ( $>95 \%$ of fragments), but some microbeads and other plastic fragments were also observed (Fig. 2). The mean concentration of microplastic fragments recovered in all 10 sediment samples was 33 fragments per $400 \mathrm{~g}$ wet weight of sediment (or 0.22 fragments per g dry weight). The maximum microplastic abundance observed was 56 fragments per $400 \mathrm{~g}$ wet weight (or 0.45 fragments per $g$ dry weight). Although the samples with the greatest microplastic concentrations were those with lower mean particle size and higher organic content, there was no significant correlation between the number of pieces of microplastic per g dry weight or mean grain size ( $p=0.51, \rho=-0.24$; Fig. 4 ). The percent organic matter content was also not significantly related to the number of microplastic fragments per $g$ dry weight $(p=0.84, \rho=-0.08$; Fig. 4). 

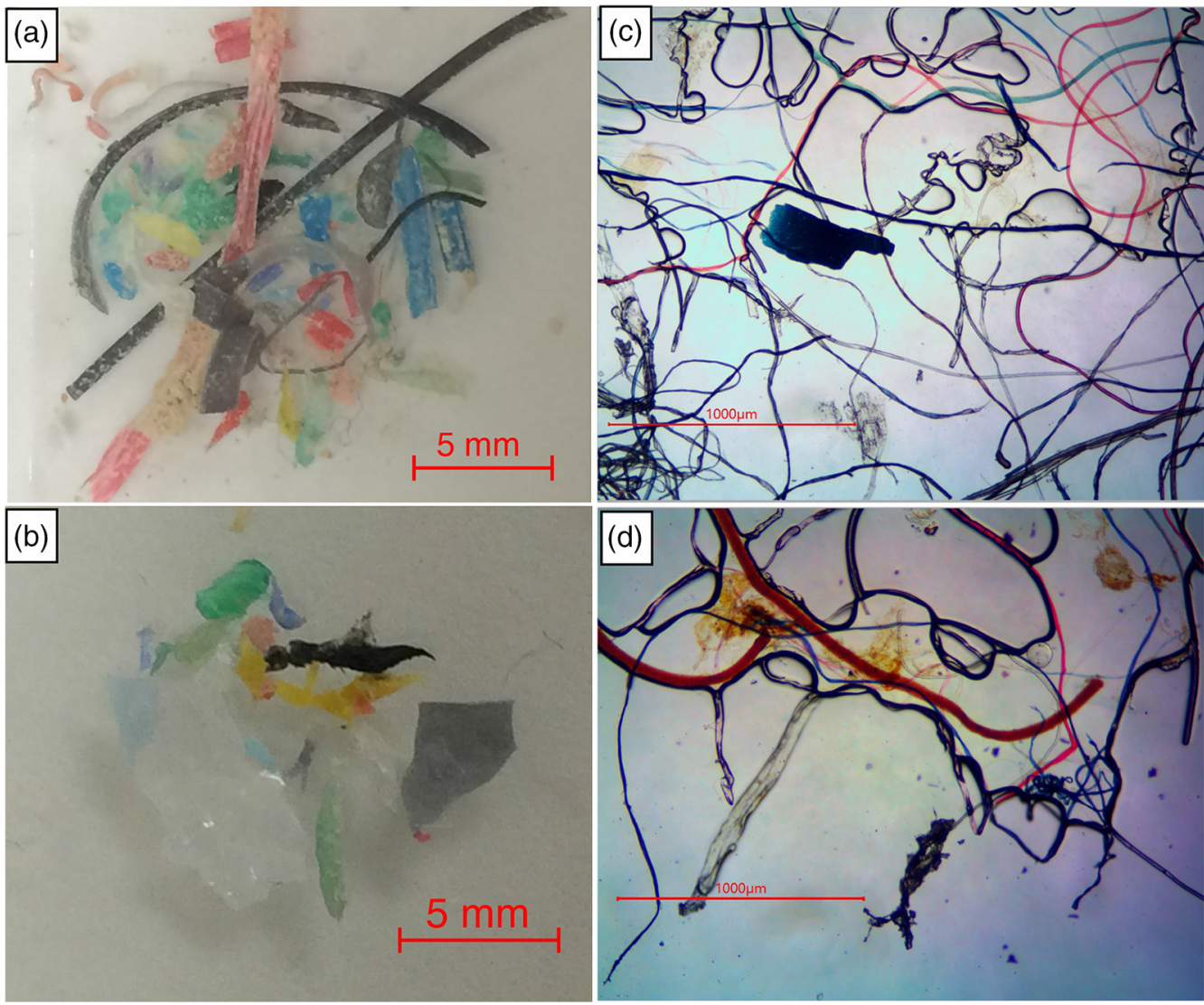

Fig. 2. Examples of microplastics recovered during sampling. Photos (a) and (b) show examples of secondary plastic fragments found in the Manta net sampling, and photos (c) and (d) show examples of the plastic particles recovered from the sediment samples. Plastic microfibers as shown in photos (c) and (d) were the most common plastic particles observed in the samples.

\section{Discussion}

Our research shows that plastic pollution is prevalent in the Ottawa River and its tributaries, with microplastics recovered in every water and sediment sample analyzed. Based on Manta net sampling, plastic concentration in the Ottawa River was greater than that reported in the Great Lakes (Eriksen et al. 2013), but less than the tributaries to the Great Lakes or more heavily populated rivers in the United States (Moore et al. 2002; Baldwin et al. 2016) (Fig. 3). Although microplastics were present in every sample, sampling methodology influenced the estimated microplastic concentration of the river, with the smaller volume bottle samples $(100 \mathrm{~L})$ taken nearshore being an order of magnitude greater than the open water samples taken with a Manta trawl. Therefore, to compare microplastic pollution among studies it is important that similar methodologies are used. For microplastic concentrations in the sediment, the depositional environment (mean particle size) and organic content of the sediment had little influence on the concentration of plastic in the sediment, suggesting that other factors are important for predicting microplastic deposition in the sediment.

Concentrations of microplastics reported in this study (mean of 1.35 fragments per $\mathrm{m}^{3}$ based on the larger volume Manta net sampling) are greater than have been reported in the Great Lakes 


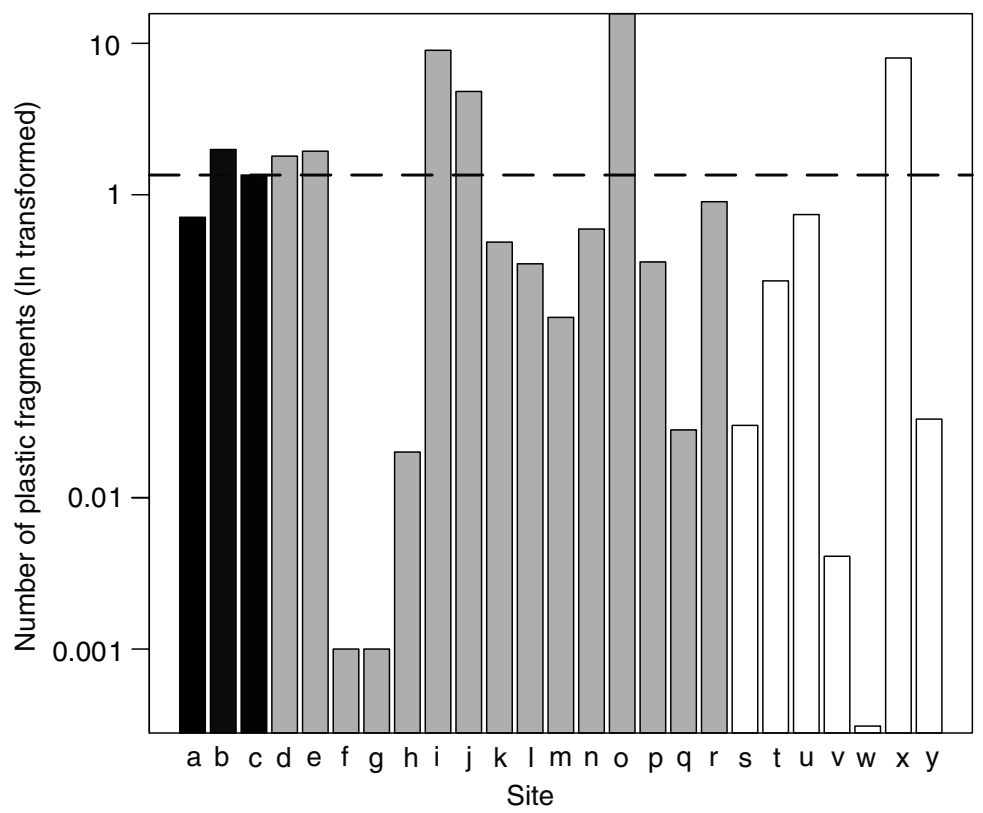

Fig. 3. Concentration of microplastics, on a log scale, recorded in the Ottawa River using the Manta net samples (black) compared with concentrations reported in other freshwater systems (dark grey) and marine environments (white). Letter along the $x$-axis refers to (a) Ottawa River upstream of effluent plume (this study); (b) Ottawa River downstream of effluent plume (this study); (c) mean concentration for the Ottawa River (this study); (d) Great Lakes tributaries (median; Baldwin et al. 2016); (e) North Shore Channel, Chicago (McCormick et al. 2014); (f) Lake Superior (Eriksen et al. 2013); (g) Lake Huron (Eriksen et al. 2013); (h) Lake Eerie (Eriksen et al. 2013); (i) Los Angeles River, California (Moore et al. 2011); (j) Upstream Ruhr River, Germany (Dris et al. 2015); (k) Weser River, Germany (Dris et al. 2015); (l) Marne and Seine rivers, France (Dris et al. 2015); (m) Lippe River, Germany (Dris et al. 2015); (n) Wupper River, Germany (Dris et al. 2015); (o) Emscher River, Germany (Dris et al. 2015); (p) Swiss rivers (Faure et al. 2012); (q) Tamar Estuary, UK (Sadri and Thompson 2014); (r) Rhine River (mean) France/Germany/Switzerland (Mani et al. 2015); (s) Eastern North Pacific (Goldstein and Goodwin 2013); (t) Northwest Mediterranean (Collignon et al. 2014); (u) North Sea (Magnusson and Norén 2014); (v) North Atlantic Gyre (Law et al. 2010); (w) Gulf of Maine, Atlantic Ocean (Law et al. 2010); (x) California Coast (Moore et al. 2002); and (y) California Current System (Gilffillan et al. 2009).

(Eriksen et al. 2013), the San Gabriel River in the United States (0.002 fragments per $\mathrm{m}^{3}$; Moore et al. 2002), and the Danube River (0.8 fragments per $\mathrm{m}^{3}$; Lechner et al. 2014), but generally lower than reported in the North Shore Channel in Chicago, Illinois, USA (1.94-17.93 fragments per $\mathrm{m}^{3}$; McCormick et al. 2014), and much lower than has been reported from heavily urbanized California rivers (30-12 000 fragments per $\mathrm{m}^{3}$; Moore et al. 2002). Similar to marine environments, as predicted by Jambeck et al. (2015), given the increasing production and use of plastic, it is likely that plastic pollution of freshwater systems including the Ottawa River will increase in the future.

The types of plastic fragments, dominated by red and blue microfibers, found in the sediment samples resembled what was recovered in the open water sampling, suggesting that the microplastics in the sediment settled out of the water column despite the plastics being less dense than freshwater. It may be that microplastics in the open water environment aggregate together with particulate organic and settle out of the water column. Comparing the abundance of microplastics recovered in the Ottawa River sediment with other freshwater studies is somewhat complicated by the unit of measure. 

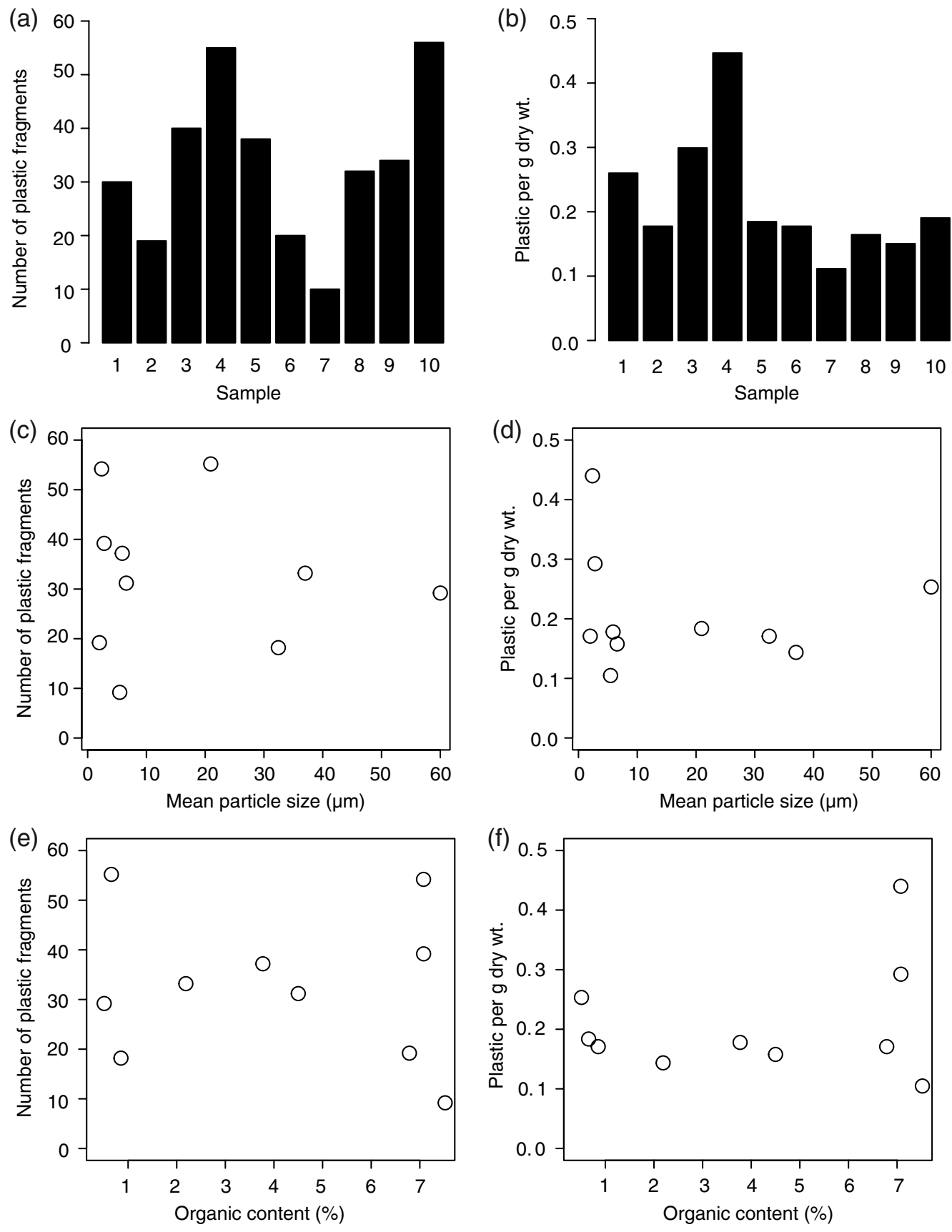

Fig. 4. (a) Number of plastic fragments found per $400 \mathrm{~g}$ wet weight of sediment at the 10 sampling sites, (b) number of plastic fragments per g dry weight of sediment at the 10 sampling sites, (c) relationship between the sediment mean particle size and the number of plastic fragments found per $400 \mathrm{~g}$ wet weight of sediment, (d) relationship between the sediment mean particle size and the number of plastic fragments found per g dry weight of sediment, (e) relationship between the sediment organic content and the number of plastic fragments found per $400 \mathrm{~g}$ wet weight of sediment, and (f) relationship between the sediment organic content and the number of plastic fragments found per g dry weight of sediment. 
We found a mean of 0.22 plastic fragments per $\mathrm{g}$ dry weight in the Ottawa River, which is comparable with what has been reported in German rivers (0.34-0.64 fragments per g dry weight; Wagner et al. 2014). Other freshwater studies of microplastics in sediment have tended to express their values on an areal basis (Anderson et al. 2016), but as an approximate comparison, our values appear greater than those from Great Lake sediments 0-34 fragments per $\mathrm{m}^{2}$ (Zbyszewski et al. 2014) but lower than sediments from the St. Lawrence River (mean of 13822 fragments per m² $^{2}$; Castañeda et al. 2014).

The concentration of microplastics recovered in the sediment samples was not significantly related to either the sediment particle size or the organic content of the sediment. It therefore appears that the depositional environment has little influence on the concentration of microplastics settling out of the water column into the sediment. It may be that the majority of these plastic particles are settling out of the water in larger aggregates of microplastics mixed with particulate organic and inorganic material, giving the aggregate a greater density and allowing the plastic to settle out under greater water velocities, although this would need to be examined in another study. An additional possibility is that our sample size was too small to give us the statistical power to detect a significant trend given the variability in the data. A post hoc power analysis indicated that a sample size of 60 would be required to adequately test the effect of depositional environment on microplastic concentrations given the variability observed in this study.

Although the impact of microplastics on freshwater ecosystems is poorly understood (Wagner et al. 2014; Anderson et al. 2016), it is clear that some freshwater organisms are consuming this plastic pollution (Holland et al. 2016), and given what has been observed in marine environments (Provencher et al. 2015; Lönnstedt and Eklöv 2016) it is plausible that they are having some detrimental impacts on freshwater organisms. Few toxicological studies have investigated the impact of microplastics on freshwater organisms and this remains a major knowledge gap in our assessment of water quality for the protection of aquatic life (Anderson et al. 2016). Au et al. (2015) investigated the impact of microplastics on Hyalella azteca, an amphipod crustacean, and found that microfibers were significantly more toxic than microbeads to the organism due to the longer residence time of the fibers in the gut of the organism, although all forms of microplastic displayed a toxic effect. This is worrying given that the vast majority of plastic particles recovered in our study were microfibers, but at concentrations that were orders of magnitude lower than those used by Au et al. (2015) in their acute and chronic exposure experiments. The greater prevalence and toxicity of plastic microfibers is also a concern because this form of plastic pollution is even more difficult to control than secondary plastics and microbeads, whose concentrations may be partially reduced through improved waste management and public policy phasing out the use of microbeads in cosmetics. Microfibers on the other hand come from multiple sources (Browne et al. 2011) and are easily transported into aquatic system both by runoff and by atmospheric deposition (Browne et al. 2011; Gasperi et al. 2015).

It is also of note that many of our tap water control samples also had a small amount of microplastic in the sample (one or two fibers per $100 \mathrm{~L}$ filtered). It is plausible that these fibers were in the tap water and are not a source of contamination, as microplastic pollution has even been reported in beer purchased in a German supermarket (Liebezeit and Liebezeit 2014). The city of Ottawa gets its drinking water from the Ottawa River; however, the city filters their drinking water through a $1.0 \mu \mathrm{m}$ filter, which should remove all but the smallest plastic fragments from the river water. Although post-filter contamination of the drinking water with microplastics is entirely plausible, another possibility is that these samples became contaminated with small amounts of microplastics during the sampling or in the lab. Although efforts were taken to prevent contamination during the sampling and in the lab (using pre-inspected filters, sterile bags, and always keeping samples covered), microplastic fibers are common in the air and atmosphere, with indoor air samples reporting microplastic fiber 
concentrations in the range of 3-15 particles per $\mathrm{m}^{3}$ (Gasperi et al. 2015). It is an important point that the microplastics reported in air quality testing were always microfibers (Gasperi et al. 2015), which were the only types of plastic particles observed in our tap water samples. Due to the high prevalence of microplastic fibers in the air, it is important when sampling aquatic microplastics to limit open contact with the air as much as possible to limit contamination. It is also important to consider that smaller sample sizes are more prone to having large relative errors due to lab contamination by a single microplastic fiber. Therefore, whenever possible, large volume samples should be employed to get the best estimate of microplastic concentrations in the system. To account for possible contamination, we recommend running control samples such as the tap water samples used in this study. This should provide a representative background contamination level based on plastic concentrations at the sampling site and in the laboratory's air.

\section{Conclusions}

Our study has shown that plastic pollution of the Ottawa River and its major tributaries in Canada's National Capital Region is prevalent and at concentrations greater than have been reported for many other freshwater systems including the Great Lakes. Our study contributes to a growing body of research (reviewed by Wagner et al. 2014 and Anderson et al. 2016) that suggests that microplastic pollution of freshwater ecosystems may be ubiquitous. It is therefore important that we develop reliable and repeatable methods for sampling and the reporting of microplastic pollution, and that we increase our understanding of the spatial and temporal variability of plastic pollution in freshwater systems. In addition, the effects of microplastic pollution, if any, on freshwater ecosystems and human health remain an important knowledge gap in our management of water quality for the protection of aquatic life.

\section{Acknowledgements}

We would like to thank Brian Bezaire for making the wastewater effluent sampling possible. This research was supported by an NSERC Discovery Grant to JCV, an NSERC USRA to CP, and a Carleton University Deans Summer Research Internship to SMH. The Ottawa Wavemakers (Hub Ottawa and WWF), Evergreen Freshwater Grant Program and Muskoka Brewery, TD Friends of Environment Foundation, and The 5 Gyres Institute provided support to MM.

\section{Author contributions}

Conceived and designed the study: JCV, CP, SMH, OH, MM. Performed the experiments/collected the data: JCV, CP, SMH, OH, MM. Analyzed and interpreted the data: JCV, MM. Contributed resources: JCV, MM. Drafted or revised the manuscript: JCV, CP, MM.

\section{Competing interests}

The authors have declared that no competing interests exist.

\section{Data accessibility statement}

All relevant data are within the paper.

\section{References}

Anderson JC, Park BJ, and Palace VP. 2016. Microplastics in aquatic environments: implications for Canadian ecosystems. Environmental Pollution, 218: 269-280. PMID:27431693. doi:10.1016/j, envpol.2016.06.074. 
Au SY, Bruce TF, Bridges WC, and Klaine SJ. 2015. Responses of Hyalella azteca to acute and chronic microplastic exposures. Environmental Toxicology and Chemistry, 34(11): 2564-2572. doi:10.1002/ etc.3093.

Baldwin AK, Corsi SR, and Mason SA. 2016. Plastic debris in 29 Great Lakes tributaries: relations to watershed attributes and hydrology. Environmental Science \& Technology, 50(19): 10377-10385. doi:10.1021/acs.est.6b02917.

Barnes DKA, Galgani F, Thompson RC, and Barlaz M. 2009. Accumulation and fragmentation of plastic debris in global environments. Philosophical Transactions of the Royal Society B: Biological Sciences, 364(1526): 1985-1998. doi:10.1098/rstb.2008.0205.

Blott SJ, and Pye K. 2001. GRADISTAT: a grain size distribution and statistics package for the analysis of unconsolidated sediments. Earth Surface Process and Landforms, 26(11): 1237-1248. doi:10.1002/ esp.261.

Browne MA, Crump P, Niven SJ, Teuten E, Tonkin A, Galloway T, et al. 2011. Accumulation of microplastic on shorelines worldwide: sources and sinks. Environmental Science \& Technology, 45(21): 9175-9179. doi:10.1021/es201811s.

Castañeda RA, Avlijas S, Simard MA, and Ricciardi A. 2014. Microplastic pollution in St. Lawrence River sediments. Canadian Journal of Fisheries and Aquatic Sciences, 71(12): 1767-1771. doi:10.1139/cjfas-2014-0281.

Cole M, Lindeque P, Halsband C, and Galloway TS. 2011. Microplastics as contaminants in the marine environment: a review. Marine Pollution Bulletin, 62(12): 2588-2597. doi:10.1016/j. marpolbul.2011.09.025.

Collignon A, Hecq J-H, Galgani F, Collard F, and Goffart A. 2014. Annual variation in neustonic micro- and meso-plastic particles and zooplankton in the Bay of Calvi (Mediterranean-Corsica). Marine Pollution Bulletin, 79(1-2): 293-298. doi:10.1016/j.marpolbul.2013.11.023.

Dris R, Imhof H, Sanchez W, Gasperi J, Galgani F, Tassin B, et al. 2015. Beyond the ocean: contamination of freshwater ecosystems with (micro-)plastic particles. Environmental Chemistry, 12(5): 539-550. doi:10.1071/EN14172.

Eriksen M, Mason S, Wilson S, Box C, Zellers A, Edwards W, et al. 2013. Microplastic pollution in the surface waters of the Laurentian Great Lakes. Marine Pollution Bulletin, 77(1-2): 177-182. doi:10.1016/j.marpolbul.2013.10.007.

Faure F, Corbaz M, Baecher H, and de Alencastro LF. 2012. Pollution due to plastics and microplastics in Lake Geneva and in the Mediterranean Sea. Archives des Sciences, 65(1): 157-164.

Gasperi J, Dris R, Mirande-Bret C, Mandin C, Langlois V, and Tassin B. 2015. First overview of microplastics in indoor and outdoor air [online]. Available from https://hal-enpc.archives-ouvertes. fr/hal-01195546.

Gilffilan LR, Ohman MD, Doyle MJ, and Watson W. 2009. Occurrence of plastic micro-debris in the Southern California current system. California Cooperative Oceanic Fisheries Investigations Reports, 50: $123-133$.

Goldstein MC, and Goodwin DS. 2013. Gooseneck barnacles (Lepas spp.) ingest microplastic debris in the North Pacific Subtropical Gyre. PeerJ, 1: e184. PMID:24167779. doi:10.7717/peerj.184. 
Gregory MR. 1996. Plastic 'scrubbers' in hand cleansers: a further (and minor) source for marine pollution identified. Marine Pollution Bulletin, 32(12): 867-871. doi:10.1016/S0025-326X(96) $00047-1$.

Heiri O, Lotter AF, and Lemcke G. 2001. Loss on ignition as a method for estimating organic and carbonate content in sediments: reproducibility and comparability of results. Journal of Paleolimnology, 25(25): 101-110. doi:10.1023/A:1008119611481.

Holland ER, Mallory ML, and Shutler D. 2016. Plastics and other anthropogenic debris in freshwater birds from Canada. Science of the Total Environment, 571: 251-258. doi:10.1016/j. scitotenv.2016.07.158.

Jambeck JR, Geyer R, Wilcox C, Siegler TR, Perryman M, Andrady A, et al. 2015. Marine pollution. Plastic waste inputs from land into the ocean. Science, 347(6223): 768-771. doi:10.1126/ science.1260352.

Law KL, Morét-Ferguson S, Maximenko NA, Proskurowski G, Peacock EE, Hafner J, et al. 2010. Plastic accumulation in the North Atlantic Subtropical Gyre. Science, 329(5996): 1185-1188. doi:10.1126/science.1192321.

Lechner A, Keckeis H, Lumesberger-Loisl F, Zens B, Krusch R, Tritthart M, et al. 2014. The Danube so colourful: a potpourri of plastic litter outnumbers fish larvae in Europe's second largest river. Environmental Pollution, 188: 177-181. PMID:24602762. doi:10.1016/j.envpol.2014.02.006.

Liebezeit G, and Liebezeit E. 2014. Synthetic particles as contaminants in German beers. Food Additives and Contaminants. Part A, Chemistry, Analysis, Control, Exposure \& Risk Assessment, 31(9): 1574-1578. doi:10.1080/19440049.2014.945099.

Lönnstedt OM, and Eklöv P. 2016. Environmentally relevant concentrations of microplastic particles influence larval fish ecology. Science, 352(6290): 1213-1216. doi:10.1126/science.aad8828.

Magnusson K, and Norén F. 2014. Screening of microplastic particles in and down-stream a wastewater treatment plant. Report number C55 for IVL Swedish Environmental Research Institute Ltd.

Mani T, Hauk A, Walter U, and Burkhardt-Holm P. 2015. Microplastics profile along the Rhine River. Scientific Reports, 5: 17988. PMID:26644346. doi:10.1038/srep17988.

Masura J, Baker J, Foster G, and Arthur C. 2015. Laboratory methods for the analysis of microplastics in the marine environment: recommendations for quantifying synthetic particles in waters and sediments. NOAA Technical Memorandum NOS-OR\&R-48.

McCormick A, Hoellein TJ, Mason SA, Schluep J, and Kelly JJ. 2014. Microplastic is an abundant and distinct microbial habitat in an urban river. Environmental Science \& Technology, 48(20): 11863-11871. doi:10.1021/es503610r.

Moore CJ, Moore SL, Weisberg SB, Lattin GL, and Zellers AF. 2002. A comparison of neustonic plastic and zooplankton abundance in southern California's coastal waters. Marine Pollution Bulletin, 44(10): 1035-1038. doi:10.1016/S0025-326X(02)00150-9.

Moore CJ, Lattin GL, and Zellers AF. 2011. Quantity and type of plastic debris owing from two urban rivers to coastal waters and beaches of Southern California. Journal of Integrated Coastal Zone Management, 11(1): 65-73. 
Plastics-the Facts. 2016. An analysis of European plastics production, demand and waste data [online]. PlasticsEurope, 35 p. Available from http://www.plasticseurope.org/documents/document/ 20161014113313-plastics_the_facts_2016_final_version.pdf.

Provencher JF, Bond AL, and Mallory ML. 2015. Marine birds and plastic debris in Canada: a national synthesis and a way forward. Environmental Reviews, 23(1): 1-13. doi:10.1139/er-2014-0039.

R Development Core Team. 2016. R: a language and environment for statistical computing. R Foundation for Statistical Computing, Vienna, Austria [online]: Available from http://www. R-project.org.

Rios LM, Moore C, and Jones PR. 2007. Persistent organic pollutants carried by synthetic polymers in the ocean environment. Marine Pollution Bulletin, 54(8): 1230-1237. doi:10.1016/j. marpolbul.2007.03.022.

Sadri SS, and Thompson RC. 2014. On the quantity and composition of floating plastic debris entering and leaving the Tamar Estuary, Southwest England. Marine Pollution Bulletin, 81(1): 55-60. doi:10.1016/j.marpolbul.2014.02.020.

Sigler M. 2014. The effects of plastic pollution on aquatic wildlife: current situations and future solutions. Water, Air, \& Soil Pollution, 225(11): 2184. doi:10.1007/s11270-014-2184-6.

Thompson RC, Swan SH, Moore CJ, and vom Saal FS. 2009. Our plastic age. Philosophical Transactions of the Royal Society B: Biological Sciences, 364(1526): 1973-1976. doi:10.1098/ rstb.2009.0054.

Wagner M, Scherer C, Alvarez-Muñoz D, Brennholt N, Bourrain X, Buchinger S, et al. 2014. Microplastics in freshwater ecosystems: what we know and what we need to know. Environmental Sciences Europe, 26(1): 12. doi:10.1186/s12302-014-0012-7.

Waters CN, Zalasiewicz J, Summerhayes C, Barnosky AD, Poirier C, Gałuszka A, et al. 2016. The Anthropocene is functionally and stratigraphically distinct from the Holocene. Science, 351(6269): aad2622. doi:10.1126/science.aad2622.

Zbyszewski M, Corcoran PL, and Hockin A. 2014. Comparison of the distribution and degradation of plastic debris along shorelines of the Great Lakes, North America. Journal of Great Lakes Research, 40(2): 288-299. doi:10.1016/j.jglr.2014.02.012. 